\title{
Designing Songs for Teaching and Learning English: A Literature Review
}

\author{
Pham Ngoc Son \\ Ho Chi Minh City University Of Food Industry, Ho Chi Minh City, Viet Nam \\ Tran Tin Nghi \\ Ho Chi Minh City University Of Food Industry, Ho Chi Minh City, Viet Nam
}

\begin{abstract}
This paper presents the theoretical backgrounds covering the theories of material design, which is useful for understanding of the effective material and the steps to produce it, and mentioning the theories of learning, which include foci on the language, the learners, and learning process. The paper aslo addresses a relationship among factors that contribute to teaching and learning process by using songs as English language teaching material. The authors review the benefits of songs and music under the lights of the cognitive, linguistic, and pedagogical levels through the material design model suggested by Hutchinson and Waters (1987). This paper contributes to the understanding of designing songs as a tool for teaching and learning English.
\end{abstract}

Keywords: Songs, Music, Material design, Cognitive process, Motivation A material design model

DOI: $10.7176 /$ JLLL/61-10

Publication date:October $31^{\text {st }} 2019$

\section{INTRODUCTION}

Writing a material for teaching is a creative process, which is meaningful to every teacher (Goatly, 2000). Teachers understand the learners' needs as well as their preferred learning styles best; therefore, as material writers, teachers can produce effective materials that help the learners overcome the problems in studying English and improve the English skills more easily. Moreover, in the process of writing materials for specific groups of learners, all teachers can teach themselves (Tomlinson, 2012). Teachers can figure out the best ways to teach; they also know how to solve the learners' problems appropriately (Hidalgo, Hall, \& Jacobs, 1995).

According to Tomlinson $(1994,2012)$ and Cunningsworth (1995) an effective material is the one that helps learners feel at ease and develop their confidence. If learners feel tense, anxious, or uncomfortable, they can easily lose opportunities for language learning. Thus, it is hard for learners to improve English skills. In order to help them overcome this difficulty, a material should be provided with texts and illustrations familiar to daily situations in the learners' cultures. Besides, a good material should require the learners' self - investment. Through their effort, interest, and attention in the learning activities, learners can profit most. That many styles of learners in the same class cause a great deal of difficulties requires a material designed with various kinds of activities; therefore, to achieve communicative purposes, a material should provide learners with opportunities to use target language.

Jolly in Tomlinson (2012) believes that an effective material must be based on a thorough understanding of learners' needs. This material can help learners overcome their difficulties in languages and in their styles of learning. Choosing a course book and using it without careful selection seems to be ineffective. Instead, teachers should produce their own materials to serve their particular groups of learners because no one but teachers understand their own learners best. By using their own material during teaching process, teachers can minimize the dissatisfaction, loss of confidences, and learning failure.

Bell and Gower in Tomlinson (2012), Celce and Olshtain (2000) think that an effective course book should give cultural contexts and text-topics that are not irrelevant to learners. According to these authors, teachers play an important role in choosing and using a course book. Teachers must decide if they should supplement, animate, or delete parts of the course book appropriately. An effective course book must integrate all four English skills and the languages used in this book should be natural, i.e. it should come from "native speakers communicating naturally."

\section{DESIGNING AN EFFECTIVE MATERIAL FOR ENGLISH LANGUAGE TEACHING}

Before designing a course, Hall (1995) emphasizes on the needs that a materials writer must pay attention, including the need to communicate, the need for long-term goals, the need for authenticity, and the need for student-centeredness. According to Hall, the need to communicate is at the heart of learning a language. This 
need requires three conditions: something to communicate, someone to communicate with, and some interest in the outcome of the communication. The long-term needs of learners are that they can communicate confidently not only in the classroom but also in real situations outside the classroom. Thus, teachers should teach the learners how to learn effectively outside the classroom. The language classroom, to Hall, has three components the teacher, the learners, and the materials. The learners must be the active component in the learning process because the learners themselves exactly know their own needs and interests. Hence, material writers should pay much attention on the way to help the learners develop their inventiveness and participation in the learning process.

Hutchinson and Water (1987) think that the most important step that materials writers consider before they start writing materials is the three basic questions under three main headings: Language descriptions, Theories of learning and Needs analysis. Hutchinson shows the relationship of the three in the figure below:

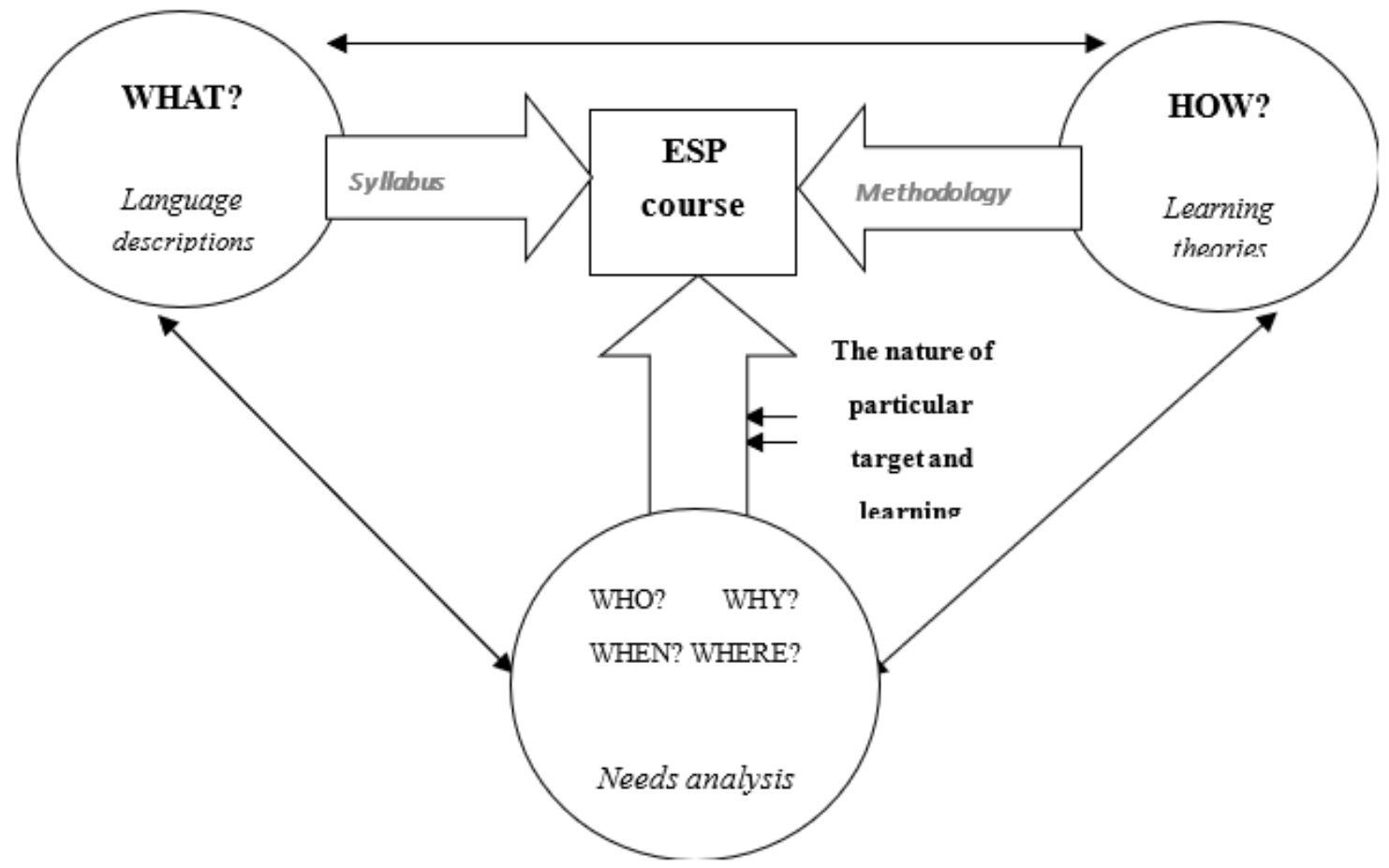

Figure 1. Factors affecting English for specific purpose course design (Hutchinson \& Waters, 1987, p. 22)

According to Hutchinson, language description is the way in which the language system is broken down so that people can study it for learning. Hutchinson concludes that there are three levels consisted in all communication: a structural level, a functional level, and a discourse level. Hutchinson believes in the difference between learners' performance and learners' competence, which contributes to the success of learners in studying a language. Learning theories provide the theoretical basis for the methodology by helping us understand how people learn. Hutchinson emphasizes on three learning theories: behaviorist approach, cognitive approach, and affective criteria. He thinks that a material writer should combine all the three learning theories in designing a material. Needs analysis, in Hutchinson's opinion, is very important because it helps material writers produce effective materials that serve the learners better. Hutchinson states that needs analysis is a complex process, involving both target situation needs concerned with language use and learning needs dealt with the way our learners learn to do what they do with language.

Hutchinson gives out two models of material design consisting of four main elements: Input, content focus, language focus and task. The relationship of these elements is shown in two figures below. 


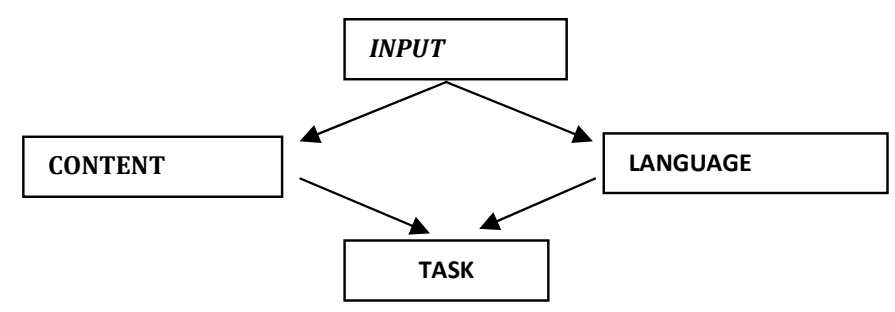

Figure 2: A material design model (Hutchinson \& Waters, 1987, p. 109)

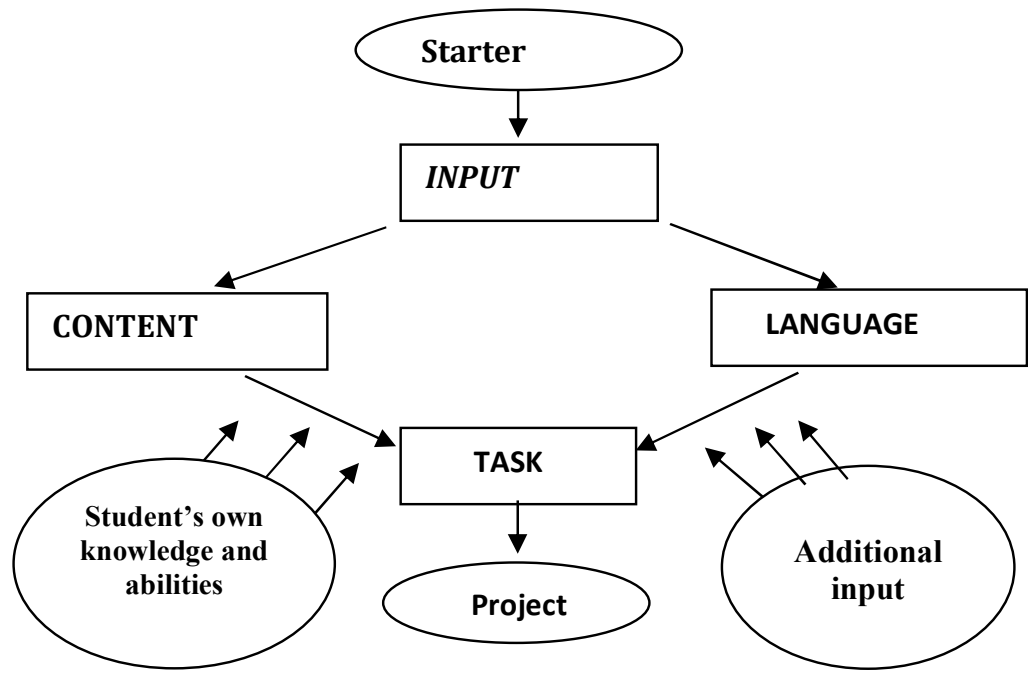

Figure 3: An expanded material design model (Hutchinson \& Waters, 1987, p. 118)

In Hutchinson's opinion, Figure 2 can be considered the nucleus of a material model. Depending on the purposes, the input can be chosen from any piece of communication data. It can provide learners with opportunities to use their information processing skills and use their existing knowledge of both the language and subject matter. The content and language are drawn from the input: Content focus is a means of conveying information and feelings about something; whereas, language focus, consisting of sentence structures, function or text construction, provides learners with opportunities to take the language to pieces, study how it works and practice putting it back together again. The two elements are selected according to what learners will need to perform the task, which is seen as the primary focus of the unit. Task, to Hutchinson, is the ultimate purpose of language learning. It can lead learners to use the content and language knowledge they have built up through the unit effectively.

In order to refine the material, Hutchinson suggests putting some other elements that can be seen in Figure 3 . The starter plays a number of important roles: It creates a context of knowledge for the comprehension of the input; it arouses the learners' interests in the topic; it activates the learners' minds and gets them thinking. Project is an expanded part to give learners the chance to apply the knowledge gained to their own situation. It means that after the unit, learners can apply what they studied in similar situations.

Dumitrescu (2000) thinks when designing or choosing a suitable material for the learners, teachers should pay attention to three basic aspects of learners' backgrounds, consisting of linguistic background, knowledge background, and cultural background. This author believes that linguistic background influences classroom management, the selection of task, the focus of micro skill instruction; knowledge background determines the need for specificity of information in the selected materials; cultural background affects trainee-instructor interaction. He also adds two additional factors that influence the final decision of what materials to incorporate into specific language tasks: Applicability and adaptability. Applicability refers to the relationship between the content of the material with the learners' field of employment. Adaptability refers to the ease of task design and ease of text manipulation. 
Hutchinson (1987, pp. 124-125) gives out ten stages to write a material, including:

Stage 1: Find your text, basing on three criteria:

- The text should be a naturally occurring piece of communication or a piece that might have occurred naturally.

- It should be suited to the learners' needs and interests.

- It should be capable of generating useful classroom activities.

Stage 2: Think of the task that the learners could do at the end of the unit.

Stage 3: Go back to the syllabus. Is the task the kind of activity that will benefit your learners?

Stage 4: Decide what language structure, vocabulary, functions, content the input contains. What aspects of language and content can be usefully focused on in the exercises?

Stage 5: Think of some exercises and activities to practice the items you have identified.

Stage 6: Go back to the input. Can it be revised in any way to make it more useful? If nothing emerges, put it in cold storage and look for another text.

Stage 7: Go through stage 1 - 6 again with the revised input.

Stage 8: Check the new materials against the syllabus and amend accordingly.

Stage 9: Try the materials in the classroom.

Stage 10: Most importantly, revise the materials in the light of the classroom use. There is no such thing as perfect materials. They can always be improved.

\section{THEORIES OF SECOND LANGUAGE LEARNING}

There is a need to pay attention to theories of second language learning, which helps material designers as well as the teacher understand better about the factors contributing to success of a teaching and learning process.

Two theories are reviewed. The first one will mention three essential elements in any successful language learning experience suggested by Nunan (1999); the second one should be about three internal factors affecting on second language learning raised by Dulay, Burt, and Krashen (1982)

\subsection{Three essential elements in successful language learning experience}

According to Nunan (1999), there are three essential elements in any successful language learning experience: language, learners, and learning process. It is believed that teachers only play a crucial role in language learning contexts; they are not essential to the learning process.

\subsubsection{Focus on language knowledge}

Celce and Olshtain (2000) suggests three main resources of language that interact in ways that manifest themselves through discourse: Grammar, vocabulary, and phonology

Richards, Platt, and Plat (2010) think of grammar as the first issue to be considered in language. It is normally believed that the essence of language lies in grammar, which is defined as 'a description of the structure of a language and the way in which linguistic units such as words and phrases are combined to produce sentences in the language. It usually takes into account the meanings and functions these sentences have in overall system of the language. It may or may not include the description of the sounds of a language.' Nunan (1999, p. 99) emphasizes on the relationship between grammar and discourse: 'Grammar and discourse are tied together in a fundamentally hierarchical relationship with lower-order grammatical choices being driven by higher-order discoursal ones.' There are three dimensions of grammar to be considered, including form, meaning, and use. Hence, it is suggested that learners must be encouraged to explore the relationship of three interlinked dimensions via tasks designed to help learners explore the functioning of grammar in context and assist learners in using the developing grammatical competence in the creation of coherent discourse.

The second issue in language comes to vocabulary. Vocabulary, as part of the language system, is interrelated with grammar. It is thought by proponents of comprehensive-based approach that an extensive vocabulary can enable learners to outperform their competence, i.e. learners can obtain meaning from spoken and written texts more efficiently.

The third one in language is pronunciation, which plays an essential role in helping learners improve listening skill. Pronunciation and listening are believed to be in complementary relationship. Learners should be taught two features of phonology, called segmental phonology, which has to do with the individual sounds of the language, and suprasegmental phonology, which has to do with stress, rhythm, and intonation patterns in the language. The suprasegmental aspect of the sound system plays an important role in communication: Faulty stress, rhythm, and intonation patterns can cause failure in improving listening skill effectively.

It is clearly seen that vocabulary, grammar, and phonology should be interrelated. Celce and Olshtain (2000) believe that 'in most instances of communication, all of the language resources are deployed simultaneously to create discourse. When language inaccuracies occur, the intended message may be comprehended because the 
contextual support is clear and unambiguous.' Hence, learners should be encouraged to use all their language resources to produce and interpret situated and purposeful discourse both within and outside the classroom.

Nunan draws some pedagogical implications from the interrelation of the three language resources as follows:

- Learners are exposed to authentic samples of language so that grammatical features one is trying to teach are encountered in a range of different linguistic and experiential contexts.

- It is not assumed that once learners have been drilled in a particular form, they have acquired it, and drilling, if it is used, is seen only as a first step toward eventual mastery.

There are opportunities for recycling of language forms, and learners are engaged in tasks designed to make transparent the links between form and function.

- Learners are given opportunities to develop their own understandings of the grammatical principles of English by progressively structuring and restructuring the language through inductive learning experiences that encourage them to explore the functioning of grammar in context.

- Over time, learners encounter target language items in an increasingly diverse and complex range of linguistic and experiential environments.

(Nunan, 1999, p. 142)

\subsubsection{Focus on learners}

Learners play an important role in learning process. Hence, there is a need to pay much attention to learners, which includes three main issues: Learner needs, learner roles and contributions, and learner choices.

Richards, Platt, J., and Platt, H. (2010, pp. 242-243) define needs analysis (needs assessment) as 'the process of determining the needs for which a learner or group of learners requires a language and arranging the needs according to priorities.' According to Brinkley (as cited in Nunan, 1999, p. 149) needs can be analyzed into two groups: 'objective' needs and 'subjective' needs. 'Objective' needs are those that can be diagnosed by teachers on the basis of the analysis of personal data about learners along with information about their language proficiency and pattern of language uses. 'Subjective' needs, which often include wants, desires, expectations, or other psychological manifestations of a lack, cannot be diagnosed easily, or, in many cases, even stated by learners themselves. Nunan (1999) also suggests the distinction between 'content' needs and 'process' needs. Content needs include the selection and sequencing of topics, grammar, function, notions, and vocabulary traditionally the domain of syllabus design; process needs refer to the selection and sequencing of learning tasks and experiences - traditionally seen as the domain of methodology. There is another useful distinction between initial needs and ongoing needs. Initial needs analysis is that carried out before a course begins; ongoing needs analysis refers to the often relatively informal analysis carried out by teachers once a course has begun.

Nunan believes that although the course objectives, materials, the teacher, room, and time of day are the same, no two classes are ever the same, which can be caused by the different role expectations that the participants (the teacher and learners) have of themselves and others in the group. Tony Wright (as cited in Nunan, 1999, p. 156) can identify two aspects of role: The first relates to social and interpersonal factors; the second relates to the learning tasks, particularly the teacher and learners expectations about the nature of the learning tasks, and the ways that they are dealt with in the classroom. These two factors will interact constantly to create a dynamic and unstable environment that can either facilitate the learning process or seriously impair it. The role expectations of participants may depend on individual personality factors. It should be believed that learner roles as active constructors of their own knowledge must be important, which can create a better learning environment for learners and the teacher to cooperate effectively in learning process. Tony Wright suggests that learners' expectations about the nature of learning tasks and the way in which individuals and groups deal with learning tasks should be an important aspect of the dynamics of the classroom.

The difference between an effective and an ineffective language user is that effective learners make appropriate choices when it comes to the means through which they learn language. Thus, learning to make informed choices is an important skill for all learners to develop (Nunan, 1999, p. 164). There is a negotiation between the teacher and learners, i.e. the views of the learners and the pedagogical agenda of the the teacher are satisfied through a process of give-and-take. According to Nunan, negotiation is a continuous process, which can be done by incorporating a series of steps into the educational process. Nunan also suggests nine steps in moving learners along the negotiation continuum as follows:

- Step 1: Make instruction goals clear to learners

- Step 2: Allow learners to create their own goals

- Step 3: Encourage learners to use their second language outside classroom

- Step 4: Raise awareness of learning process

- Step 5: Help learners identify their own preferred styles and strategies

- Step 6: Encourage learner choice

- Step 7: Allow learners to generate their own tasks.

- Step 8: Encourage learners to become teachers 


\section{- Step 9: Encourage learners to become researchers}

Kirschner, Sweller and Clark (2006) claims there are five attributes of an effective learner: self-directed, inquisitive/ curious, self-aware/ honest with self, risk-taking/ not afraid of making mistakes, and open-minded.

Of all five attributes, self-direction is the most important to the learning process. They believe that if learners can envision how a certain skill or class will help them in long run, they can motivate themselves to take more pride in their day-to-day work.

Asking questions and being inquisitive is also essential to the learning process because the process involved in formulating a question often helps crystallize a new concept in learners' mind.

They also believe the essence of self-awarness. If learners are confused about something, they need to admit that they do not have the answers and go look for help, which can help them become better at whatever they are trying to accomplish.

Learners need to take mistakes in stride as part of the learning process because if they are afraid of making mistakes, they will not engage their mind fully in training courses; thus, they will not learn as much in long run.

Finally yet importantly, good learners need to be open-minded. Learners will enhance the ability to learn if they are willing to look at a problem from a different perspective though they may not agree with it.

They conclude that the five attributes mentioned above can help learners much in opening their mind and getting more knowledge.

\subsubsection{Learning process}

One of the most important factors in learning process is learning strategies, the mental and communicative procedures learners use in order to learn and use language. Strategies to the learning process are very important because if learners are conscious of the processes underlying the learning learners are involved in, the learning will be more effective. It should be believed that learners who are taught the strategies underlying their learning are more highly motivated, more self-confident in learning. Rebecca Oxford (as cited in Nunan, 1999, p. 172) identifies 12 key features of language learning strategies:

1. contribute to the main goal, communicative competence

2. allow learners to become more self-directed

3. expand the role of teachers

4. are problem-oriented

5. are specific actions taken by the learner

6. involve many actions taken by the learners, not just cognitive

7. support learning both directly and indirectly

8. are not always observable

9. are often conscious

10. can be taught

11. are flexible

12. are influenced by a variety of factors

Nunan (1999) thinks that 'underlying every task that one introduces into the classroom is a learning strategy of one kind or another.' A typology of commonly used learning strategies should be developed as follows:

\begin{tabular}{|l|l|}
\hline COGNITIVE & $\begin{array}{l}\text { Putting things that are similar together in groups } \\
\text { Example: Study a list of names and classify them into male and female }\end{array}$ \\
\hline Predicting & $\begin{array}{l}\text { Predicting what is to come in the learning process } \\
\text { Example: Look at unit title and objectives and predict what will be learned }\end{array}$ \\
\hline Inducing & $\begin{array}{l}\text { Looking for patterns and regularities } \\
\text { Example: Study a conversation and discover the rule for forming the simple } \\
\text { past tense }\end{array}$ \\
\hline Taking notes & Writing down the important information in a text in your own words \\
\hline Concept mapping & Showing the main ideas in a text in the form of a map \\
\hline Inferencing & Using what you know to learn something new \\
\hline Discriminating & Distinguishing between the main idea and supporting information \\
\hline Diagramming & Using information from a text to label a diagram \\
\hline INTERPERSONAL & \multicolumn{2}{|l|}{} \\
\hline Cooperating & $\begin{array}{l}\text { Sharing ideas and learning with other students } \\
\text { Example: Work in small groups to read a text and complete a table }\end{array}$ \\
\hline Role-playing & $\begin{array}{l}\text { Pretending to be somebody else and using the language for the situation you } \\
\text { are in }\end{array}$ \\
\hline
\end{tabular}




\begin{tabular}{|c|c|}
\hline & $\begin{array}{l}\text { Example: You are a reporter. Use the information from the reading to interview } \\
\text { the writer }\end{array}$ \\
\hline \multicolumn{2}{|l|}{ LINGUISTIC } \\
\hline Conversional patterns & Using expressions to start conversations and keep them going \\
\hline Practicing & $\begin{array}{l}\text { Doing controlled exercises to improve knowledge and skills } \\
\text { Example: Listen to a conversation, and practice it with a partner }\end{array}$ \\
\hline Using context & $\begin{array}{l}\text { Using the surrounding context to guess the meaning if unknown words, } \\
\text { phrases, and concepts }\end{array}$ \\
\hline Summarizing & Picking out and presenting the major points in a text in summary form \\
\hline Selective listening & $\begin{array}{l}\text { Listening for key information without trying to understand every word } \\
\text { Example: Listen to a conversation and identifying the number of speakers }\end{array}$ \\
\hline Skimming & $\begin{array}{l}\text { Reading quickly to get a general idea of a text } \\
\text { Example: Decide if a text is a newspaper article, a letter, or an advertisement }\end{array}$ \\
\hline \multicolumn{2}{|r|}{ - } \\
\hline Personalizing & $\begin{array}{l}\text { Learners share their own opinions, feelings, and ideas about a subject } \\
\text { Example: Read a letter from a friend in need and give advice }\end{array}$ \\
\hline Self-evaluating & $\begin{array}{l}\text { Thinking about how well you did on a learning task, and rating yourself on a } \\
\text { scale }\end{array}$ \\
\hline Reflecting & Thinking about ways you learn best \\
\hline \multicolumn{2}{|l|}{ CREATIVE } \\
\hline Brainstorming & $\begin{array}{l}\text { Thinking of as many new words and ideas as you can } \\
\text { Example: Work in group and think of as many occupations as you can }\end{array}$ \\
\hline
\end{tabular}

Table 1: A typology of learning strategies (Nunan, 1999, pp. 83-84)

It can be concluded that learners have an important role in learning process, i.e. the success of a learning process should lie on learners' effort to get knowledge. Hence, as suggested by Nunan (1999), Celce and Olshtain (2000), and Hutchinson (1994), it is necessary to design tasks and final projects that can encourage learners to be independent in learning. Teachers should create a better learning environment, in which learners may have many choices to activate their active roles. A good negotiation between the teacher and learners must be paid attention to so that a learning process can be successful.

Besides three aspects of second language learning, it is also essential to have a look at three internal factors which can operate when learners learn a second language suggested by Dulay, Burt, and Krashen (1982).

\subsection{Three internal factors affecting on second language learning}

Dulay, Burt, and Krashen (1982) believes that learners' motivates, needs, attitudes, and emotional states may filter what learners hear, which has an influence on the success of learning process. There are three internal factors operate when learners learn a second language: Two subconscious processors named 'filter' and 'organizer', and one conscious processor called the 'monitor'.

The filter is that part of the internal processing system that subconsciously screens incoming language. According to Krashen, the filter determines: (1) which target language models the learner will select, (2) which parts of language will be attended to first, (3) when language acquisition efforts should cease, and (4) how fast a learner can acquire the language. There are three main parts of the filter: Learners' motives, attitudes, and emotional states. Motivation in language acquisition can be thought of as the need that the learner feels to learn the second language; three kinds of motivation affecting language acquisition are integrative motivation, instrumental motivation, and social group identification. Gardner and Lambert (as cited in Heidi Dulay; et al., 1982, p. 47) define integrative motivation as 'the desire to achieve proficiency in a new language in order to participate in the life of the community that speaks the language', instrumental motivation as 'the desire to achieve proficiency in a new language for utilitarian reasons, such as getting a job'; and the social group identification motive as 'the desire to achieve proficiency in a language or language variety spoken by a social group with which the learner identifies.' In combination with attitudes and motivation, the learner's emotional states affect what the learner admits for further processing. It is believed that the less anxious the learners are, the better language acquisition proceeds.

The organizer is that part of the internal processing system responsible for the learner's gradual organization of the new language system. Krashen thinks that in examining the language that learners produce, it is essential to see the functioning of the organizer reflected in three pervasive phenomena: (1) the transitional constructions that learners use before a structure is finally acquired, (2) the errors that systematically occur in learner speech, and (3) the common order in which mature structures are learned. 
The monitor is the part of the learner's internal system that appears to be responsible for conscious linguistic processing. Learners can use the linguistic knowledge they gain through monitoring to consciously formulate sentences and to correct or edit their speech and writing. Krashen believes that whenever conscious linguistic processing takes place, the learner is said to be using the monitor; Krashen also thinks that when a learner performs a drill that requires conscious attention to linguistic form, or when a learner memorizes a dialogue, conscious processing is taking place and the monitor is being used. The degree to which the monitor is used depends on: (1) the learner's age, (2) the amount of formal instruction the learner has experienced, (3) the nature and focus required by the verbal tasks being performed, and (4) the individual personality of the learners. Learners who are insecure, self-conscious, and afraid to make errors tend to use the monitor more than others.

In brief, the three internal processing factors mentioned above should play an essential role in the successful acquisition of the second language.

\subsection{Discussions of previous works on teaching English via songs}

Many authors from different parts of the world have mentioned teaching English via songs. Many useful aspects found in songs can give effectiveness in English teaching methodology.

Murphey (1992) emphasizes the importance of music and songs on language learning. The reasons are mentioned: First, songs are believed to strongly activate the repetition mechanism of the language acquisition device because brains have a natural propensity to repeat what can be heard in environment in order to make sense of it. Second, songs occupies everywhere in the world; thus, music and songs can be easily become part of people. Third, songs must be very relaxing, which can provide variety and fun, and encourage harmony within oneself and within a group; through songs, listeners can learn many things about different cultures, religions, patriotisms, etc. Last but not least, songs are short, self-contained texts that might be appropriate for teachers to handle in a lesson.

Garza (1995), an assistant professor and coordinator in the Department of Slavic Languages at the University of Texas at Austin, says that "Songs, like poetry, are one of the most powerful combinations in helping the learner commit limited phrases and word combinations to memory, to be put into active service at a later time in communication. Rock music videos can also be most effective in teaching pronunciation and intonation. Songs often contain the elements of repetition, rhyme and rhythm that facilitate quick memorization and easy imitation of the original text material. It is no wonder, then, that in song a "foreign accent" pronunciation is much more easily masked or eliminated than in normal conversational speech." "Via songs, we can teach students particular sounds like /th/, word final /r/, schwa, etc. or grammatical items like nouns, adjectives, plurals, etc."; "The lyrics might provide the EFL instructor with excellent material to present and practice modal construction in English." According to Garza, learners will learn in songs the way to pronounce the words exactly and have a natural intonation. Besides, learners have an opportunity to experience some particular sounds that do not exist in their first language. However, the author of this thesis does not think that choosing rock music as teaching material is a good idea. Because rock music is usually strong and loud, learners may find it hard to listen and distinguish different sounds.

Diamond and Minicz (1994), ESL consultants for the Adult Learning Resource Center in Des Plaines, Illinois also think of music as a useful source in teaching English, and these authors put an emphasis on country songs rather than rock ones. They think that country music can help the learners practice pronunciation, stress, intonation and help teachers to introduce new grammar points. More than that, Diamond also emphasizes on another aspect:

"Music brings language alive, songs provide chunks of language complete with shadings of meaning and emotion; songs release tension and allow students to enjoyably hear and repeat language again and again."

Diamond and Minicz agree that studying via songs help the learners overcome the barriers of cultures. Learners can study the language in real situations, which learners must deal with when they communicate to native speakers, which is hard to experience in textbooks. Teaching English via songs help learners know language structures, language skills and many interesting points lying beneath songs. Learners can get more experiences and feel more confident in everyday communication. Songs can be easily remembered because of its melody; hence, learners can study and remember many things from songs better than from textbooks.

Diamond emphasizes the advantages of country songs. However, if frequently used in teaching English, country songs can bring boredom to learners and troubles of understanding cultural values to teachers. Besides, country songs, now and then, contain many old words that are not used in modern life. Thus, choosing suitable songs to teach requires teacher's careful consideration.

"English through opera", written by Beliavsky (2001), an assistant professor of ESL at the Institute of ESL at St. John's University, Queens, New York, is another attractive way in teaching English.

"Opera is drama in which the text is set to music and staged. The texts of operas are sung, with singing and stage action nearly always given instrumental accompaniment. Many operas also feature instrumental interludes (called intermezzi) and dance scenes, even extended ballets that interrupt the action. Opera began as an 
entertainment at the courts of the Italian aristocracy, with outdoor terraces and even enclosed tennis courts being adapted for performances. It had its origins in the last years of the 16th century, and eventually this new form of entertainment caught on with the public. Opera as a popular entertainment attained its zenith in the 19th and early 20th centuries, after which the disruptive effects of two world wars and far-reaching developments in music itself left opera in a state of fairly arrested development. Throughout its history opera has exerted great influence on other forms of music - and vice versa." (Encarta Encyclopedia, n.d.)

From what it is known about opera, teaching English through this kind of music is believed to be so difficult. In spite of its complexity, Beliavsky still succeeds in applying opera to teach English for foreign learners. Beliavsky reasons that: "ESL students want a real life; they want real challenge. They want to hear, see, taste and touch the richness of what our world has to offer." It is true that learners need challenges because challenges bring them the confidence, the really fundamental ability. For that reason, in teaching, teachers should give learners more probational exercises that force them to think over for the answers; of course, the probation must be in their management. Using opera in teaching English is a good idea because it gives learners more knowledge of the richness of musical world. Nevertheless, as the author of this thesis mentions above, though opera has many benefits, it is challenging to be used effectively in teaching. It requires teachers a profound understanding of opera, which costs a lot of time to find out about. At least, teachers can consider this idea as the usefulness of music as well as its richness in teaching English.

As mentioned above, it is believed that remembering what have been learned is essential in second language acquisition. Music with its strong points can help learners do that. This opinion is very clear and logical. Adkins (1997) concludes: "The music provides a strong emotional association with the words, the music is enjoyable and they are motivated to learn the song." To Adkins, using music in teaching is, without doubt, a good choice. With the exposures, learners can observe clearly what can be expressed in the songs throughout singers' performance, clothes, colors, etc. This gives learners more opportunities to realize the differences among cultures.

Levine, Baxter, and McNulty (1987) think about the difficulties of cultures learners deal with when they study a foreign language. To these authors, these are barriers causing misunderstanding in contacting a new language.

"Understanding the new culture and learning to communicate comfortably in it are as important goals as learning the rules of the language. Much of culture is hidden from sight; it cannot be seen. Culture is like an iceberg, most of which is deep within the ocean just as much of culture is deep within people. Some cultural differences can be seen right away; these are like the tip of the iceberg. Learning to communicate well across cultures means becoming aware of the hidden parts of culture."

Hence, with the help of video music, besides all the skills can be achieved, learners can know more about cultures. Learners can realize the similarities and the differences in culture via exposures rather than via speech only. It is known that the meanings of non-verbal communication are different from cultures to cultures and that non-verbal is very necessary in communication, which accounts for approximately three quarters of communication. Thus, during teaching process, teachers need to give learners some knowledge about non-verbal language and its meanings in conversation. Teaching how to use a language effectively is really a challenge because language is like an iceberg; what can be seen is only the tip of that iceberg. Hence, teachers should enrich the lectures with 'the part of the iceberg that is hard to be seen', i.e. culture. Milano (1994) also suggests a teaching technique including four steps that can help teachers teach English via music successfully. First, it is a need to explain briefly the background about the story, the context, and the characters of the song learners are going to listen to. Second, teachers play the cassette player and let learners listen to the song, and then arrange the phrases in the order in which learners are heard. Third, after learners are familiar with the melody, they are required to write their own stanza to substitute some information in the songs while maintaining the rhyme of the music. Finally, the the teacher and learners can sing the song together.

The importance of music and songs in language learning can be found in Murphey (1992, pp. 6-8), who believes that songs can be easily remembered and become part of learners. Murphey gives out ten advantageous points of music and songs in language learning:

(1) To sing with vocalizations is significantly easier than speech; it seems easier to sing language than to speak it

(2) Music and songs are extremely important in the development of language in young children.

(3) 'I often call songs 'adolescent motherese'. 'Motherese' is the highly affective and musical language that adults use with infant. As children grow up, they get less and less of this. At adolescent, they appear to be adult and go through many changes which seem to reduce the amount of affective 'motherese' speech they receive. Songs may to a certain extent replace this, filling a need that not only adolescents have, but which all of us have throughout our lives.'

(4) Music and songs may occupy ever more of the world around us

(5) Songs may work on our short and long-term memory

(6) Songs may strongly activate the repetition mechanism of the language acquisition device 
(7) Songs in general use simple, conversational language, with a lot of repetition, which is just what many language teachers look for in sample texts

(8) Songs can be appropriated by listeners for their own purpose; songs happen whenever and wherever one hears them and they are, consciously or subconsciously, about the people in one's own life

(9) Songs are relaxing; they provide variety and fun, and encourage harmony within oneself and within a group

(10) For language teachers, songs are short, which are easy to handle in a lesson.

In summary, via many opinions of different authors, many useful aspects of using music in teaching and learning English can be clearly seen. Not only is music a means of helping learners improve English skills but music is also a means of recreation. Music can give learners relaxation; music can also help learners be more confident in daily communication, in contacting and understanding different cultures. The usefulness of songs in teaching and learning English is beyond imagination. With such many useful aspects, English songs should be used as materials in teaching and learning English.

\section{SUGGESTIONS}

Choosing good songs to be designed as teaching and learning materials, which can help improve all four skills, should be a challenge. Teachers are required to spend so much time and patience. Murphey (1992, pp. 8-9) thinks that different teachers have different ideas about teaching and learning English using musical materials. However, it is commonly believed that there are 20 concerns of the teacher about using music and songs in language teaching and learning:

1. Administrators/ teachers/ students do not take music and song seriously.

2. It disturbs neighbouring classes.

3. Some students get too excited.

4. It takes away from the normal syllabus. Time is lost.

5. Students disagree about songs, and have different musical tastes.

6. Pop songs have poor vocabulary - too much slang and bad grammar.

7. How do you exploit the material usefully? What is the goal?

8. It is hard to find lyrics - sources of 'old' recorded material are no longer available.

9. Students just want to listen, not to work.

10. Poor quality cassette/ video recorder.

11. Lack of technical equipment due to cost.

12. Teachers do not like to sing or are not musical.

13. Many songs are not intelligible.

14. EFL songs are boring.

15. Students will not sing.

16. Which songs should you choose? Many express violence and sexism.

17. What to do when students bring music which teachers hate?

18. Songs go out of date very quickly.

19. How do you get other teachers involved?

20. How do you share in materials production?

From concerns of the teacher drawn out by Murphey, there are some points that need paying much attention:

- Songs can be used as input to help improve integrated skills, i.e. there is a requirement to exploit material designed from English songs to improve English skills subconsciously; thus, singing in classroom should be considered inessential.

- There are two important aspects to be mentioned: First, learners should achieve language skills and language knowledge with material designed from songs; second, material should be designed carefully.

\section{CONCLUSION}

Many aspects of English songs have been examined. The authors initially assumed that English songs would benefit learners' language skills. Not only do songs help learners overcome tiredness but also encourage them to improve the four language skills. Songs can be used as a good tool to teach English; teaching and studying English via songs must be one of the most effective ways. Besides, songs supposed to be effective in teaching listening skill can be used to improve other skills as well.

Firstly, the opinions of effective materials were reviewed. Then, models of designing English for specific purpose (ESP) materials suggested by Hutchinson (1994) were illustrated with explanations. The two models of Hutchinson should be the basic background for an English song to be designed as a teaching and learning material for ELT classes. 
Secondly, theories of second language learning were put in consideration, which may play an essential role in designing appropriate tasks and projects that can encourage learners to participate in learning process actively and independently. In this part, suggestions given by Nunan (1999) were highly focused on, especially the typology of learning strategies and learner roles in learning process.

Thirdly, many various ideas of teaching and learning, using English songs as input were discussed. Via the discussion, effectiveness of songs in helping all the four skills were found; experiences of teaching English via songs were mentioned and discussed, which is very useful for further researches in the future,

Last but not least, the concerns of teachers about using music and songs in language classroom presented by Murphey (1992) were also reviewed, which aims to help material designers meet the criteria for choosing songs designed as teaching and learning materials discussed in coming researches.

\section{BIBLIOGRAPHY}

Adkins, S. (1997). Connecting the Powers of Music to the Learning of Languages. The Journal of the Imagination in Language Learning, IV.

Cunningsworth, A. (1995). Choosing Your Coursebook. Macmillan.

Diamond, J. ., \& Minicz, E. (1994). Country Songs: Music, Language, and Life. The Journal of the Imagination in Language Learning, 2. Retrieved from https://studylib.net/doc/8241155/review-63-fall-winter-20082009---the-northeast-conferenc...

Dumitrescu, V. (2000). Authentic Materials. English Teaching Forum, 38, 21-25.

Encarta Encyclopedia. (n.d.). Microsoft Encarta Reference Library 2003 Takes the Work Out of Homework Stories. Retrieved July 22, 2019, from https://news.microsoft.com/2002/06/27/microsoft-encartareference-library-2003-takes-the-work-out-of-homework/

Garza, T. J. (1995). Beyond MTV: Music videos as foreign language text. Journal of the Imagination in Language Learning. Retrieved from https://www.academia.edu/1974906/Beyond_MTV_Music_videos_as_foreign_language_text

Goatly, A. (2000). Critical reading and writing: an introductory coursebook. Retrieved from https://www.worldcat.org/title/critical-reading-and-writing-an-introductory-coursebook/oclc/859536685

Hall, J. K. (1995). (Re)creating our Worlds with Words: A Sociohistorical Perspective of Face-to-Face Interaction. Applied Linguistics, 16(2), 206-232. https://doi.org/10.1093/applin/16.2.206

Heidi Dulay;, Burt;, M., \& Krashen, S. (1982). Language Two. Retrieved from https://www.amazon.com/Language-Two-Heidi-Dulay-1982-05-

05/dp/B01N0BQK8M/ref=sr_1_1?keywords=Dulay\%2C+Burt\%2C+and+Krashen+\%281982\%29.\&qid=1 $563735042 \& s=$ books \&sr $=1-1$

Hidalgo, A. C., Hall, D., \& Jacobs, G. M. (1995). Getting started: materials writers on materials writing. SEAMEO Regional Language Centre. Retrieved from https://books.google.com.vn/books/about/Getting_Started.html?id=kf9mAAAACAAJ\&redir_esc=y

Hutchinson, T., \& Torres, E. (1994). The textbook as agent of change. ELT Journal, 48(4), 315-328. https://doi.org/10.1093/elt/48.4.315

Hutchinson, T., \& Waters, A. (1987). English for Specific Purposes. Cambridge: Cambridge University Press. https://doi.org/10.1017/CBO9780511733031

Kirschner, P. A., Sweller, J., \& Clark, R. E. (2006). Why Minimal Guidance During Instruction Does Not Work: An Analysis of the Failure of Constructivist, Discovery, Problem-Based, Experiential, and Inquiry-Based Teaching. Retrieved from http://www.cogtech.usc.edu/publications/kirschner_Sweller_Clark.pdf

Levine, D. R., Baxter, J., \& McNulty, P. (1987). The culture puzzle : cross-cultural communication for English as a second language. Prentice-Hall.

Milano, G. (1994). Teaching English through Broadway Musicals. The Journal of the Imagination in Language Learning, ii.

Murphey, T. (1992). Music \&amp; song. Oxford University Press.

Ninah Beliavsky. (2001). English Through Opera. The Journal of the Imagination in Language Learning and Teaching, $6(1)$.

Retrieved from https://www.researchgate.net/publication/334387874_English_Through_Opera_in_The_Journal_of_the_I magination_in_Language_Learning_and_Teaching_Clyde_Coreil_editor_Volume_6_2001

Nunan, D. (1999). Second language teaching \&amp; learning. Boston Mass.: Heinle \& Heinle Publishers. Retrieved from https://www.worldcat.org/title/second-language-teaching-learning/oclc/40787504

Olshtain, E., \& Celce-Murcia, M. (2000). Discourse Analysis and Language Teaching. In The Handbook of Discourse Analysis (pp. 707-724). Malden, Massachusetts, USA: Blackwell Publishers Ltd. https://doi.org/10.1002/9780470753460.ch37

Richards, J. C., \& Schmidt, R. W. (2010). Longman dictionary of language teaching and applied linguistics. Longman. 
Tomlinson, B. (1994). Pragmatic awareness activities. Language Awareness, 3(3-4), 119-129. https://doi.org/10.1080/09658416.1994.9959850

Tomlinson, B. (2012). Materials development for language learning and teaching. Language Teaching, 45(2), 143-179. https://doi.org/10.1017/S0261444811000528 